\title{
'A LIKE IS WORTH A THOUSAND WORDS': GROWTH OF INSTAGRAM AND ITS IMPACT ON YOUTH
}

\author{
Ketki Saini \\ University of Delhi, Delhi, India
}

\begin{abstract}
Social media is addictive precisely because it gives us something which the realworld lacks: it gives us immediacy, direction, a sense of clarity and value as an individual." - David Amerland

In the past few years, there has been a rapid increase in the amount of Indian youth using Instagram. Instagram now has 1 billion monthly active users. The top three countries who use Instagram are the United States, India, and Brazil. On average, as per the survey conducted as part of our research, Indian youth spend one to two hours of their day using Instagram which consequently impacts their personalities, relationships and perspectives.
\end{abstract}

This article, using facts and figures, analyses the reasons for the rapid growth of Instagram, globally and focuses more importantly on its growth in India. Also, by collecting both primary and secondary data, this article examines the impact Instagram has on the Indian youth.

Keywords-Instagram, Social Media, Youth, Impact

\section{INTRODUCTION}

Founded in 2010 by Kevin Systrom and Mike Krieger, Instagram has gained immense popularity among people globally. Instagram has witnessed a massive growth from 90 million users in January 2013 to 1000 million users in June 2018. The number of users has multiplied more than ten times. In India, there are currently 38 million users of Instagram, out of which 27 million are male and the remaining 11 million are female. Globally, Instagram ranks fourth in the list of top free apps on iOS. However, in India, the photo-sharing app is at number two, after parent Facebook in the list of top apps. Instagram is the least toxic and has more civility amongst the others. One of the 'new' social platforms, it provides specialization and motivation to its users.

This article is divided into two parts. In the first part of the article, we have used data from various sources to analyze the growth trends of Instagram globally and in India and the reasons behind the same. Then, we have attempted to make an

\author{
Purti Goswami \\ University of Delhi, Delhi, India
}

assessment of the extent and nature of impact that Instagram has on youth in India.

\section{RESEARCH METHODOLOGY}

Collection of data

In the present research, primary as well as secondary data sources are included. The primary source of data is gathered through a questionnaire. The detailed questionnaire which contained questions about different aspects of impact and growth of Instagram. The data of the questionnaire is collected from 207 participants which is the major source of primary data for the study which lead to the analysis of the reality and the gap between the negative and the positive impact of Instagram and continuous growth trends in the past years. At the same time, secondary data is provided by the literature review which is collected from already published research articles and surveys.

Sampling design and Analytical techniques

207 respondents were randomly selected of different age groups ranging from 10 - 30 years. The participants who filled the questionnaire comprises of school students, college students as well as working professionals. The results have been analysed and the statistics have been presented in the form of graphical representations.

\section{LITERATURE REVIEW}

Global Social Media Research Summary 2018 estimated that around 3.196 billion people use social media worldwide which is increasing by $13 \%$ every year. India has the second largest growth rate in social media users (31\%) after Saudi Arabia. Majority of Instagram users lie in the age group of 25-34 years. Half of the Instagram users use the application daily. Instagram topped in having average interactions per post per 1000 followers

Justin kownacki et al.( 2017) in social media survey results showcased the evident shift in usage of different networking sites from 2015 with the change in interests and preferences of the people. In 2015, twitter was the most used personal and most critical professional platform but now Instagram and Facebook have become most preferred for personal use. The customer point of view on the major source of revenue for 


\section{International Journal of Engineering Applied Sciences and Technology, 2020 Vol. 5, Issue 3, ISSN No. 2455-2143, Pages 462-468 \\ Published Online July 2020 in IJEAST (http://www.ijeast.com)}

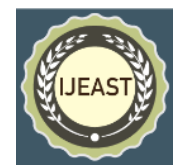

social networking sites i.e. advertisement, Instagram ads are least hated and most useful amongst the rest. In 2017 survey results, the enjoyment on YouTube and Instagram has gone up by $30 \%$ and $40 \%$ use the same channels more often. Suggestions were asked from the respondents to improve the networking on the sites, the most common suggestion was to decrease the 'toxicity, trolls and fake news' which Facebook and twitter unwillingly do which was the reason of decrease in usage of both the sites. However, the same became the reason for popularity for Instagram and YouTube, being the less toxic platforms.

According to a research by Saleem Alhabash and Mengyan Ma et al. (2017), A Tale of Four Platforms: Motivations and Uses of Facebook, Twitter, Instagramand Snapchat Among College Students, suggests that Instagram is the most used social networking application used by the participants of the survey followed by snapchat. This survey showed the intensity of usage of different sites and also the motivations of nine different uses. Entertainment was a major choice in motivation uses in all the networking sites except in Facebook which had convenience with the highest motivation. One important conclusion which was drawn during the research was the distinguish between the 'new' and 'old' networking sites. Instagram and snapchat were identified as new sites which had more specialization and diverse set of motivations and gratifications.

Amanda Lenhart et al. (2007) in the research paper, "Teens, Privacy and online social media networks" has discussed that teenagers analyse their privacy on social media platforms regarding sharing of information on their profiles. The survey conducted by the Pew internet \& American life project suggests the teenagers try to protect themselves from the risks associated with the social media networks $(66 \%$ of the social media using teenager's profile is not visible to all the internet users) but they still face potential risks like $43 \%$ of social networking teens have been contacted by complete strangers. The paper also discusses that there are different views and behaviour about privacy with respect to different genders and age groups. Girls post the pictures of themselves and with their friends whereas the male gender shares the pictures of city or town they live in or their last name and cell phone number. The younger teenagers (15-17 years) are more likely to share fake information $(69 \%)$ than the older teenagers (48\%). Amanda Lenhart highlights that the parents use technical and non-technical measures to protect their children online. $53 \%$ of parents filter the software for child use while $65 \%$ reports checking up on their teenagers after they go online.

Shahzad khan et al. (2012), Impact of Social Networking Websites on Students, reviews about the impact of the social networking sites on the academic performance of the students. The paper surveyed the core reasons of the usage of the sites amongst the students. The research found out that students having 3.0-3.5 CGPA in a 4-grade scale browses the internet for entertainment. Being influenced by the friends, the major reason $(67.3 \%)$ to use the networking sites amongst the age group of 15-25. Regarding the academic performance, survey also showcased that male gender uses social networking sites for gaining knowledge purposes as compared to female who uses it mostly for entertainment.

Monica Anderson And Jingjing Jiang et al.(2018), Teens, Social Media \&Technology,discusses the mixed impact of social media on the teenagers.

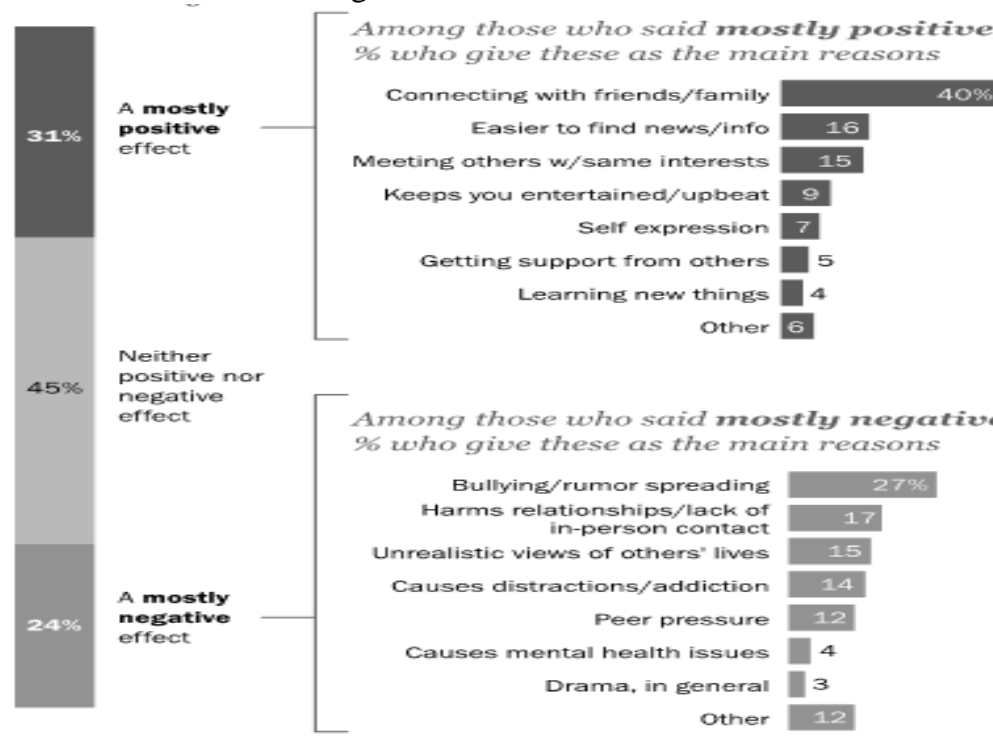

Graph-1: Percentage of U.S. teens saying Instagram has positive, neutral or negative impact on people their own age Source: Pew Research Center The graph above showcases the dilemma of the teens about its impact on them. The research also quotes an interesting fact that $95 \%$ of the teenagers use social media on their smartphones with $45 \%$ of the teens being constantly online. The literature reviewed the take-off of the virtual world with increase in users of social media year by year and different aspects of social networking sites like Facebook, Instagram, twitter, on the basis of gender, age group, academic performance of the students. Social networking sites were not supposed to have a negative connotation attached to it originally but witnessing the addiction of students poses a question on them. This research will analyse the reality and the gap between the negative and the positive impact of Instagram and particularly it's reasons for continuous growth in the past years.

\section{HISTORY OF INSTAGRAM}

Instagram was developed in San Francisco by Kevin Systrom and Mike Krieger. Kevin Systrom originally created an app called Burbn, which was used by people to check-in where they are on this mobile app. Systom was able to raise $\$ 500,000$ from various venture capital firms for his idea. He, then, decided that he needed a team to help him execute. Mike Kreiger agreed to join. However, they decided that Burbn was 


\section{International Journal of Engineering Applied Sciences and Technology, 2020 \\ Vol. 5, Issue 3, ISSN No. 2455-2143, Pages 462-468 \\ Published Online July 2020 in IJEAST (http://www.ijeast.com)}

too similar to already existing apps in the markets, so in order to give themselves an edge, they focused solely on communication through images. All other features of the app were removed and it was renamed as "Instagram." Instagram has been a great success since its inception in 2010. Throughout the years, it won many awards and gained great recognition since its pioneer year.

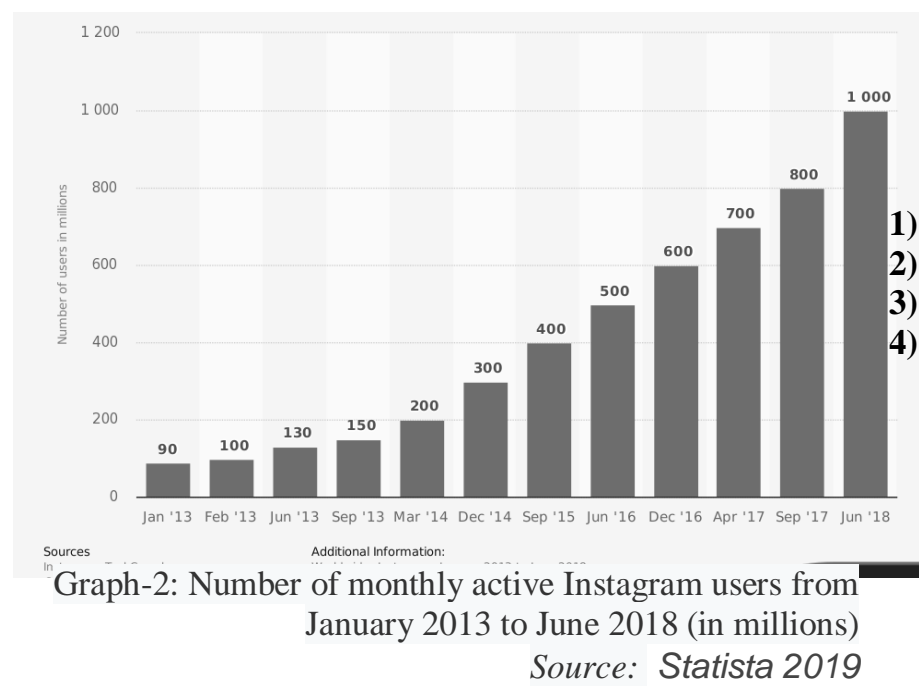

Known as one of the best business acquisitions in Silicon Valley, Instagram was acquired by Facebook for a price of $\$ 1$ billion in 2012. At the time of its acquisition, Instagram had merely 30 million followers and zero dollars in revenue, however, after five years since its acquisition, Instagram had 600 million followers and became a multibillion dollar business.

\section{REASONS OF GROWTH TRENDS}

There have been various reasons for Instagram's growth in the past seven years globally as well as in India, which have been highlighted below;

\section{1) A visual-first platform:}

Instagram is centered around the idea of sharing high quality pictures and videos, with text. On the other hand, Twitter is focused on sharing a small text complemented by a video or image. Instagram appealed to a larger number of people especially in an era when high quality cameras are one of main selling propositions of expensive smartphones.

Instagram further introduced the feature of "Instagram Stories" in August 2016. Instagram Stories is a feature that lets users post photos and videos that vanish after 24 hours. This feature is similar to the story feature in Snapchat. After the introduction of this new feature, Instagram witnessed a huge increase in the number of daily active users.

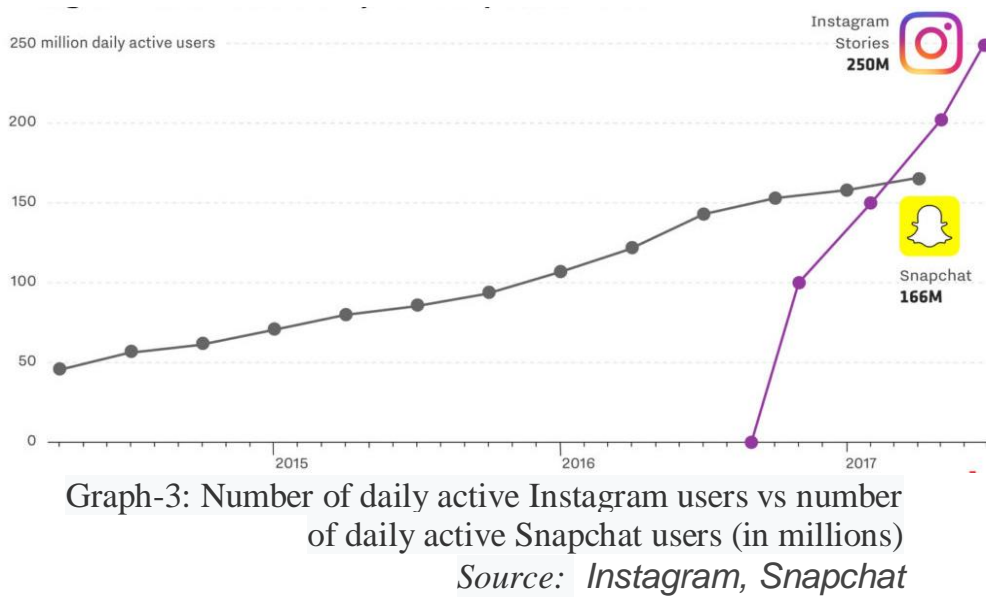

2) Access to Facebook's data, tech and financial resources:

Instagram has the benefit of access to Facebook's large data, technology and financial resources post its acquisition. It has been seen that the reason why most Twitter users quit after a while is that it can feel like a very lonely experience. Instagram has overcome this by allowing Instagram users to link their Instagram accounts with their Facebook accounts. A user can quickly follow all his or her Facebook friends who are on the platform and is also notified when a new friend joins Instagram. Consequently, users get a decent number of likes and comments on their posts and are encouraged to share more.

On being acquired by Facebook, Instagram is able to keep its infrastructure costs low by using its engineering talent. Data centers have also aided Instagram. This allows Instagram to come up with new features. Facebooks large profits help absorb short-term losses incurred by Instagram as they result in growth. On the other hand its competitor, Snapchat Inc., finds it difficult to grow its user base in emerging markets due to the cost of associated with supporting new customers.

\section{5) 3) Introduction of Reliance Jio:}

The Mary Meeker annual Internet trends report for 2017 suggests that Jio has been a driving factor in India's rapidly expanding Internet usage. The report suggests that there are now 355 million Internet users in India, with 27 percent population penetration. India now has the second highest number of Internet users in the world after China.

The major cause which results in an expansion in internet penetration is fall in Internet data prices, which was certainly spurred by the arrival of Reliance Jio.

Below shows the fall in data prices per GB for the quarters April 2014 to April 2017. It can be seen from the chart below 


\section{International Journal of Engineering Applied Sciences and Technology, 2020 Vol. 5, Issue 3, ISSN No. 2455-2143, Pages 462-468 \\ Published Online July 2020 in IJEAST (http://www.ijeast.com)}

that a steep decrease in data prices was witnessed with the onset of Reliance Jio.

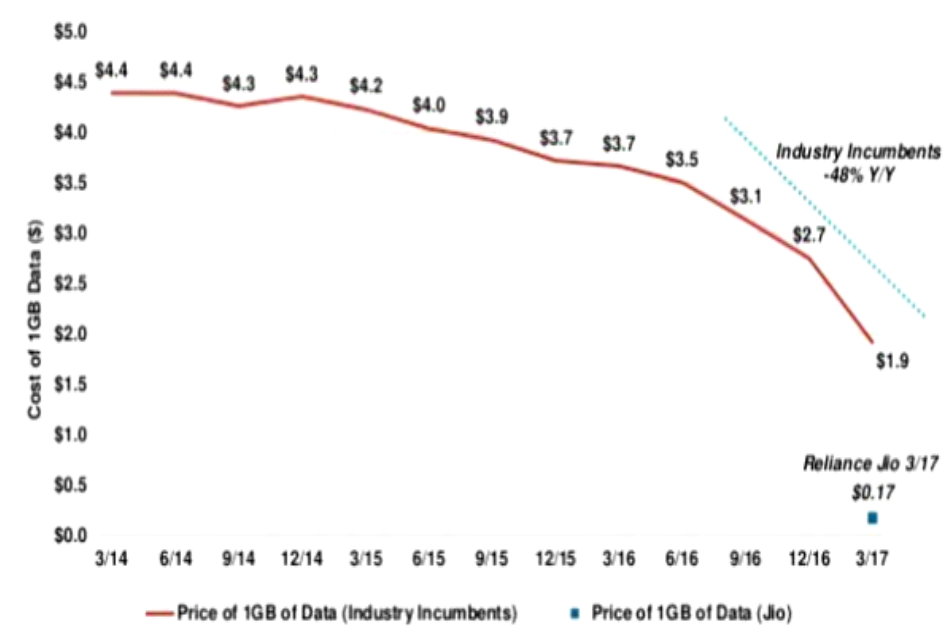

Graph-4: Data prices per GB

Source: Kleiner Perkins

The Mary Meeker report also suggests that $34 \%$ of all mobile usage time is spent for usage of social media and messaging.

\section{4) Better Technology:}

India has seen a shift in the way social media is viewed by youth due to better technology especially smartphones. The trend of declining smartphone prices over the past couple of years has made it affordable for almost everyone to buy one. On account of different smartphones being launched, some low priced smartphones have also been made available for purchase by those people who cannot afford the higher priced models. By the end of the year 2017, there were 291.6 million smartphone users. Also, by the year 2022, the number of smartphone users in India would reach 490.9 million.

\section{5) Advertisements:}

What attracts most advertisers to Instagram is its highly engaged users. As of June 2018, there are nearly 1 billion monthly active users. Though its position is behind Facebook, it is ahead of most other social network sites, including Twitter and Pinterest. On an average day, users share more than 95 million photos and videos. And these posts yield a total of about 4.2 billion likes in a single day. Forrester et al. (2015) conducted a study on how social media users engage with the top 50 global brands. They analyzed more than 2,400 posts and 11.8 million user interactions to collect useful data. From this data, they concluded that user interactions with brands are highest on Instagram when compared to every other social network.
As per a study conducted by Yotpo, Instagram users spend an average of 192 seconds. It was concluded that visitors from Instagram spend $45 \%$ longer time than visitors from Facebook and $40 \%$ longer time than visitors from Twitter.

Also, as the perspective of the youth towards social media is changing, marketers are coming up with new ways to interact with their target market and boost sales. It is due to the increase in number of Instagram users in India that the concept of "Instagram Influencers" has gained popularity in the recent past. Instagram Influencers are thought leaders in their niche or area of expertise and brands capitalize on that. Instagram Influencers have the ability to engage with a sufficient number of people and help increase a brand's profile and engagement. This is usually done by uploading sponsored posts.

\section{PRIMARY SURVEY FINDINGS:}

As per the survey conducted, $32.9 \%$ of respondents stated that they have three social media accounts, $19.8 \%$ said they have two accounts, $18.4 \%$ said they have four accounts, $13 \%$ said they have five accounts, $8.7 \%$ have five accounts and only $7.2 \%$ said they solely have one account. This signals at the growth in social media that India has witnessed in the past decade. On average, most respondents had at least three social media accounts - one of them being Instagram.

How many social media sites do you have accounts with ?

207 responses
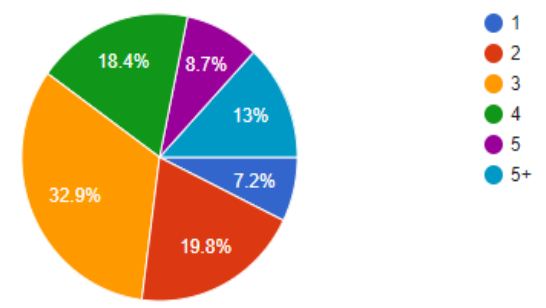

The results of our survey are supported by data collected from Statista. As per the website, it is shown that the number of social media users has been increasing at a steady rate. Also, it is expected that number of social media users will reach approximately 370.77 million by the year 2022 . 


\section{International Journal of Engineering Applied Sciences and Technology, 2020 Vol. 5, Issue 3, ISSN No. 2455-2143, Pages 462-468 \\ Published Online July 2020 in IJEAST (http://www.ijeast.com)}

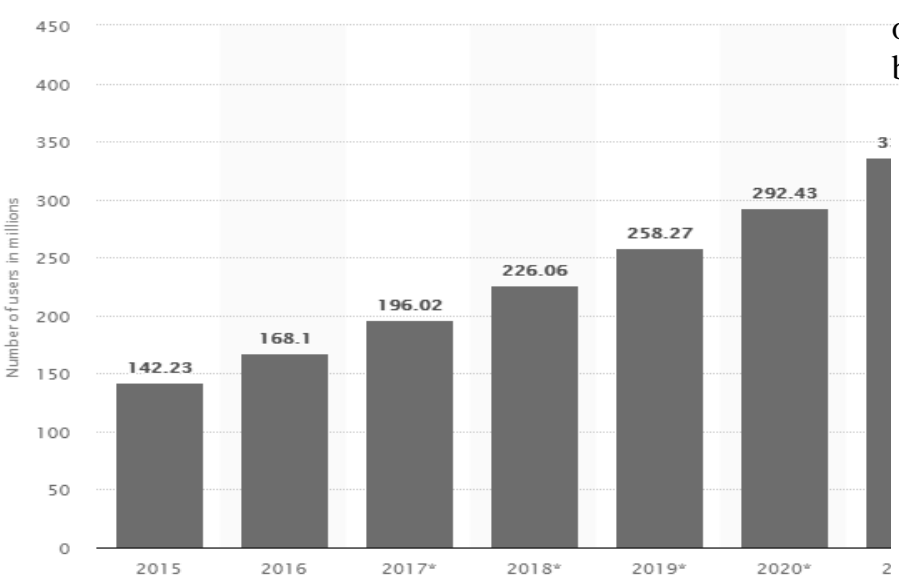

Graph-5: Number of social media users in India from 2015 to 2022(in millions)

Source: Instagram, Statista

Further, when the respondents were asked about the amount of time they spent on Instagram per day, the majority spent more than 1-2 hours bearing a total of $29 \%$, whereas $25.1 \%$ spent 30 minutes to 1 hour, $21.7 \%$ spent less than 30 minutes on Instagram, $14.5 \%$ spent $2-3$ hours per day and $9.7 \%$ spent more than 3 hours per day using the Instagram app or website. This indicates that a major part of the Indian youth spends more 1-2 hours accessing Instagram day, thereby highlighting an extensive impact of Instagram on the youth in terms of being able to attract a huge amount of the population's time per day.

\section{How much time do you spend on Instagram per day?}

\section{7 responses}

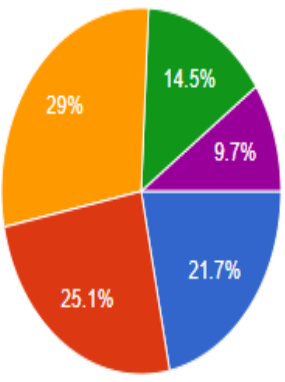

less than 30 minutes 30-60 minutes $1-2$ hours 2-3 hours $3+$ hours

In order to further analyze the reason for the popularity of Instagram among Indian youth, focus was placed on obtaining information about the time when Instagram is used. As part of the survey, we asked the respondents when they access Instagram. $94.2 \%$ of respondents said they use Instagram during free time, without any purpose, $33.8 \%$ answered that they use it whilst at work/college, $27.1 \%$ stated they used it during social occasions and the remaining $23.7 \%$ said they used Instagram during meal times. This indicates that majority of the youth uses Instagram as a medium to past time and beat boredom.

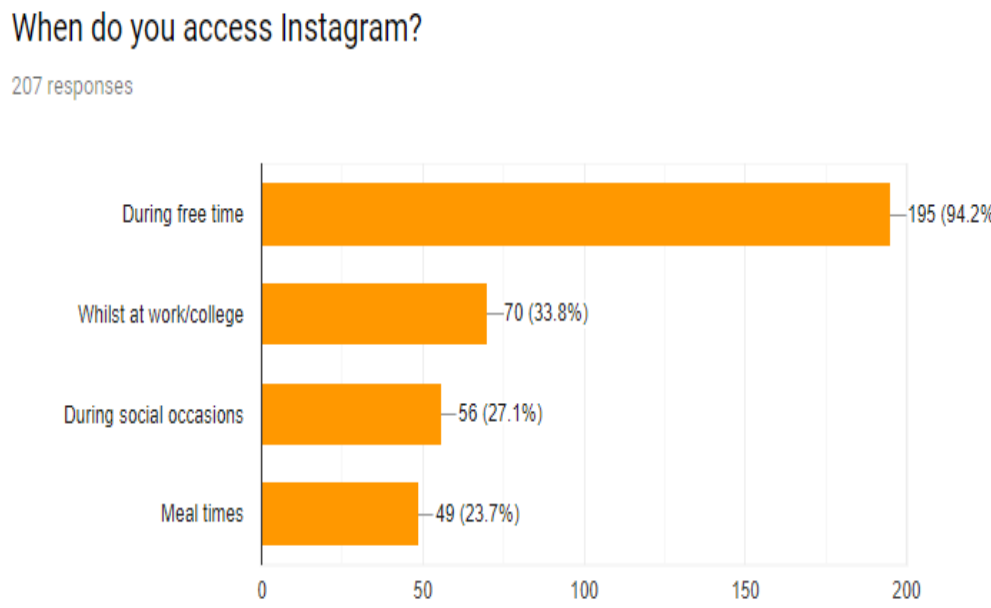

VII. IMPACT

The second half of this paper shall focus on the impact Instagram has on the youth of our country. To start with, we analyzed the need that is being satisfied by Instagram. In order to do that, it is important to know about the kind of information the youth usually derive from Instagram. As part of the survey, we asked respondents to select multiple uses for which they resort to the services of Instagram. The most frequently selected answers were posting pictures, keeping in touch with family and friends and to browse/ pass time.

The data evidently shows the inclination of the youth towards an urge of knowing as to what goes around in their near and dear ones lives and updating others on the things going on in their own lives through posting of pictures, videos and stories. This in a way helps them stay connected with the people in their life but at the same time leads to a loss of focus towards their own goals, since only a small proportion of the youth said they use Instagram for inspiration, news, buying and selling and build relations on the professional front. 
International Journal of Engineering Applied Sciences and Technology, 2020

Vol. 5, Issue 3, ISSN No. 2455-2143, Pages 462-468

Published Online July 2020 in IJEAST (http://www.ijeast.com)

What do you use Instagram for?

207 responses

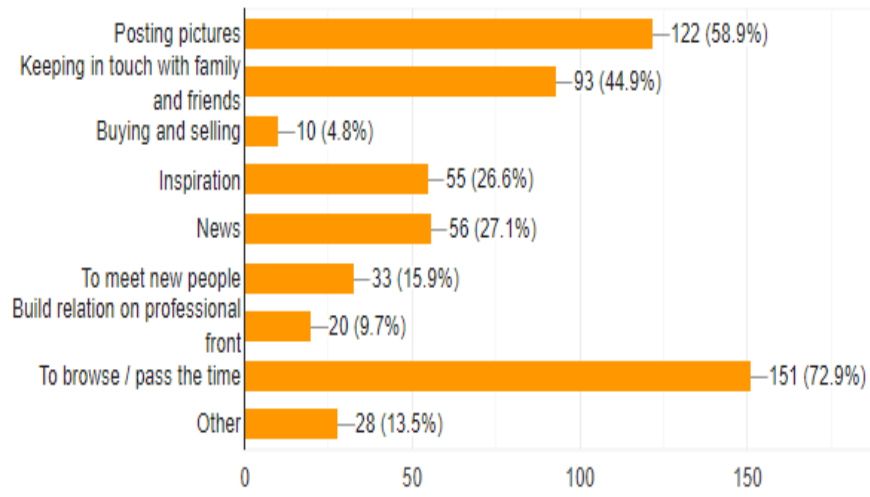

When asked about the cyber-crimes on Instagram, the results were similar to the one of the statements in the literature review which states that people prefer Instagram because it is less toxic and more civil. $82.1 \%$ participants said that they haven't encountered any kind of cyber crime on Instagram. Most occurring crime was making of fake profile (12\%) by strangers and using it in the name of another person. Hacking and photo being misused came after it respectively.

\section{Have you been a victim of a cyber crime?}

$$
207 \text { responses }
$$

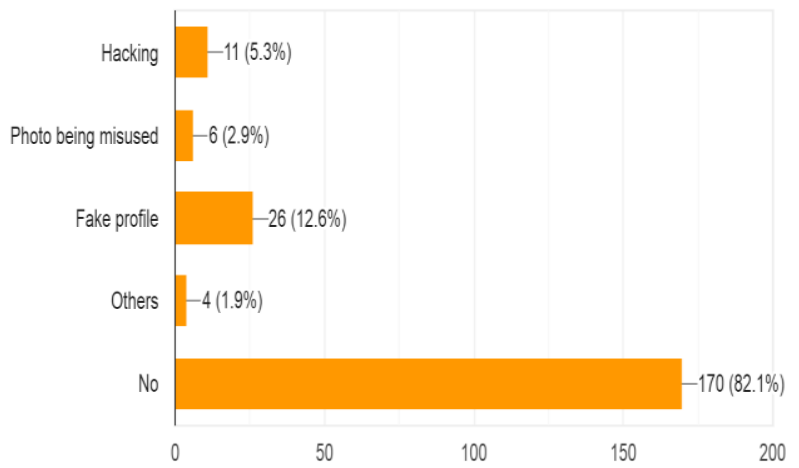

One of the questions asked in the survey was about the hampering of the social gathering by Instagram. Only $28 \%$ of participants think that it hampers a gathering of people together. This result is particular is quite amusing because a lot of studies regarding the same subject including a study by Common Sense Media claims that the teenagers will rather text the people than talking to them face to face. $61 \%$ says they would prefer texting, video calling rather than in person talking as it gives them a 'mask' or call it a 'shield'.

The respondents were asked about the effect of Instagram on a relationship which included both family, friends or romantic relationship. The results show that the relationships of most of the respondents $(61.4 \%)$ were not affected by the application.

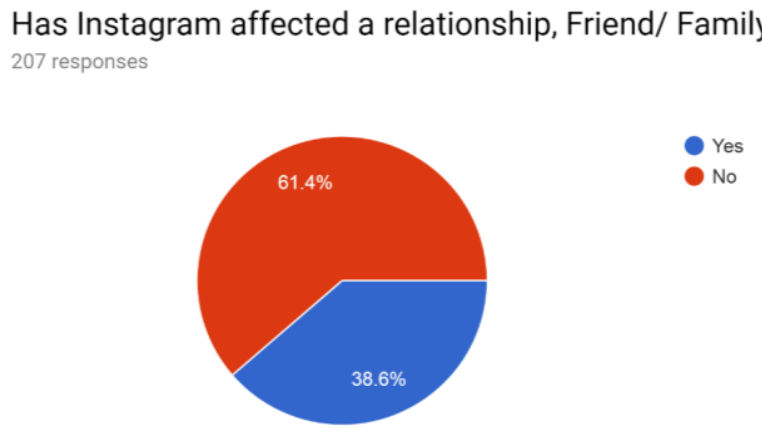

But, within the participants which had their relationships affected by Instagram, more of them were female. An interesting conclusion comes into focus that the female gender gets more affected and become the victim of depression and suicidal tendencies. Alice $G$ Walton also backs this conclusion in her study which suggests that lower level of happiness through social media is being seen in girls than boys of about 1000 families. Girls are more affected by comparisons they make between themselves and others which is the main cause of being affected by negatively.

Ironically, according our survey the positive impact of Instagram overweighs the negative one and in comparison to the male gender $(73 \%)$, more female $(80 \%)$ say that the overall impact of this application is positive even though it affects their relationships more.

\section{Which aspects according to you weigh more through Instagram? 207 responses}

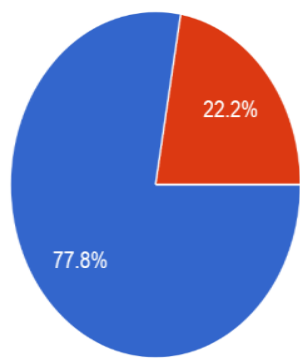

Positive

Negative

\section{CONCLUSION}

It was found that these social networking sites are acting as great medium for communication and exchanging information. The youth is given a platform to share their lives with their near and dear ones.

The primary objective of this article was to throw light on the growth trends of Instagram globally and in India, as well as, analyze the reasons for such growth over the past few years. 


\section{International Journal of Engineering Applied Sciences and Technology, 2020 Vol. 5, Issue 3, ISSN No. 2455-2143, Pages 462-468 \\ Published Online July 2020 in IJEAST (http://www.ijeast.com)}

With reference to the study, we can conclude that Instagram has grown rapidly in India due to the availability of an abundance of resources post its acquisition by Facebook, introduction of Reliance Jio in the Indian market, better technology and a change in the way of marketing.

In the second part of the article, with the aid of the data that was collected and we analyzed the impact Instagram has had on the Indian youth, comprising of both negative and positive elements. However, the positive impact outweighs the negative ones associated with this second generation of social media. Youth in India that uses Instagram experience diverse set of motivation and gratification.

\section{REFERENCES}

[1] Chaffey Dave. (2018). Global social media research summary 2018. Retrieved from https://www.smartinsights.com/social-media-

marketing/social-media-strategy/new-global-social-mediaresearch/

[2] Kownacki Justin. (2017). Social Media Survey Results. Retrieved from http://www.justinkownacki.com/social-mediasurvey-habits-change-2017/.

[3] Anderson Monica \& Jiang Jingjing.(2018). Teens, Social $\begin{array}{llll}\text { Media \& Technology 2018. Retrieved } & \end{array}$ fromhttp://www.pewinternet.org/2018/05/31/teens-socialmedia-technology-2018/.

[4] Alhabash Saleem \& Ma Mengyan. (2017). A Tale of Four Platforms: Motivations andUses of Facebook, Twitter, Instagramand Snapchat Among College Students. Retrievedfromhttps://journals.sagepub.com/doi/10.1177/20563 05117691544

[5] Lenhart Amanda \& Madden Mary. (2007). Teens, Privacy and online social media networks. Retrieved fromhttp://www.pewinternet.org/2007/04/18/teens-privacyand-online-social-networks/

[6] Khan Shahzad. (2012). Impact of Social Networking Websites on Students. Retrieved from http://www.academia.edu/8877963/Impact_of_Social_Networ king_Websites_on_Students

[7] Walton Alice G. (2018). Retrieved from https://www.forbes.com/sites/alicegwalton/2018/03/20/socialmedia-may-be-more-psychologically-harmful-to-girls-thanboys/\#4b66454d7e35

[8] Statista. (2017). Retrieved from https://www.statista.com/statistics/869009/india-share-ofinstagram-users-by-age/

[9] Khurana N. The Impact of Social Networking Sites on the Youth. Retrieved from https://www.omicsonline.org/openaccess/the-impact-of-social-networking-sites-on-the-youth2165-7912-1000285.pdf

[10] Izea. (2017). What is an Instagram Influencer. Retrieved from https://izea.com/2017/05/02/what-is-an-instagraminfluencer/
[11] Sen Sunny (2018). The India \#Insta Story. Retrieved from https://factordaily.com/the-india-instagram-story/

[12] Jhonsa Eric (2017). 5 Reasons Behind the Stunning Growth of Facebook's Instagram. Retrieved from https://www.thestreet.com/story/14410134/1/instagram-firingon-all-cylinders.html

[13] Cutler Kim-Mai. (2012). From 0 to $\$ 1$ billion in two years: Instagram's rose- tinted ride to glory. Retrieved from https://techcrunch.com/2012/04/09/instagram-story-facebookacquisition/

[14] Smith. Kit (2019). 47 Incredible Instagram Statistics. Retrieved from https://www.brandwatch.com/blog/instagram$\underline{\text { stats/ }}$

[15] Sheth Reena. (2017). Mind blowing stats about Indians on Instagram in 2017. Retrieved from https://www.socioadvocacy.com/blogs/instagram-audience-inindia-2017/\#.XE7tyFwzbIU 